\title{
Neoadjuvant Chemotherapy in Locally Advanced Cervical Cancer: Review of the Literature and Perspectives of Clinical Research
}

\author{
ANGIOLO GADDUCCI and STEFANIA COSIO \\ Department of Clinical and Experimental Medicine, \\ Division of Gynecology and Obstetrics, University of Pisa, Pisa, Italy
}

\begin{abstract}
Concurrent cisplatin-based chemotherapy and radiotherapy (CCRT) plus brachytherapy is standard treatment for locally advanced cervical cancer. Platinumbased neoadjuvant chemotherapy (NACT) followed by radical hysterectomy has been proposed as an alternative approach, especially for patients with stage Ib2-IIb disease. This review analyzes the most commonly used combination regimens in this clinical setting and the randomized trials comparing chemo-surgery versus definitive radiotherapy or CCRT. The combination of paclitaxel plus ifosfamide plus cisplatin (TIP regimen) obtained the highest rates of optimal pathological response, associated with elevated hematological toxicity. In a recent phase II study, a dose-dense regimen consisting of weekly paclitaxel plus carboplatin for 9 cycles has achieved optimal pathological response rates similar to those of TIP with better toxicity profile. Further studies are strongly warranted to better define the optimal regimen for the patients selected to receive NACT followed by radical surgery.
\end{abstract}

GLOBOCAN estimates of incidence and mortality worldwide for 36 cancers in 185 countries have shown 569,874 new cases of cervical cancer and 311,365 deaths due to this malignancy in 2018 (1). Concurrent cisplatin (CDDP)-based chemotherapy and radiotherapy (CCRT) plus brachytherapy represents the standard of care in patients with locally advanced disease, i.e. in stage

This article is freely accessible online.

Correspondence to: Angiolo Gadducci, MD, Department of Clinical and Experimental Medicine, Division of Gynecology and Obstetrics, University of Pisa, Via Roma 56, Pisa, 56127, Italy. Tel: +39 50992609, e-mail: a.gadducci@med.unipi.it

Key Words: Cervical cancer, radiotherapy, concurrent chemoradiation, neoadjuvant chemotherapy, radical surgery, review.
FIGO 2009 Ib2-IIa2-IIb-III-IVa (2-6). A meta-analysis of 13 randomized trials showed that CCRT significantly improved 5year overall disease-free survival (DFS) $[$ hazard ratio $(\mathrm{HR})=0.78$, $95 \%$ confidence interval $(\mathrm{CI})=0.70-0.87], 5$-year loco-regional disease-free survival $(\mathrm{HR}=0.76,95 \% \mathrm{CI}=0.68-0.86)$, 5-year metastases-free survival $(\mathrm{HR}=0.81,95 \% \mathrm{CI}=0.72-0.91)$ and 5 year overall survival $(\mathrm{OS}) \quad(\mathrm{HR}=0.81,95 \% \mathrm{CI}=0.71-0.91)$ compared to radiotherapy alone (7). A larger survival advantage emerged for the two further trials in which adjuvant chemotherapy was administered after CCRT. An additional trial appeared to confirm the clinical benefit of this adjuvant treatment (8). In in vitro studies gemcitabine (GEM) was found to synergize with CDDP and have a radiosensitizing effect in six cervical cancer cell lines (9). A Mexican phase III trial randomized 515 patients with stage IIb-IVa cervical cancer to receive either CCRT (with CDDP $40 \mathrm{mg} / \mathrm{m}^{2}+$ GEM $125 \mathrm{mg} / \mathrm{m}^{2}$ weekly) plus brachytherapy followed by two cycles of adjuvant chemotherapy with CDDP $\left(50 \mathrm{mg} / \mathrm{m}^{2}\right.$ day 1$)+$ GEM 1000 $\mathrm{mg} / \mathrm{m}^{2}$ (days 1 and 8 ) every 3 weeks or the standard CCRT (with CDDP $40 \mathrm{mg} / \mathrm{m}^{2}$ weekly) plus brachytherapy (8). The former arm experienced a trend significantly lower distant recurrence rate $(8.1 \%$ versus $16.4 \%, p=0.005)$ a trend to a lower local recurrence rate $(11.2 \%$ versus $16.4 \%, p=0.097)$, a significantly better progression-free survival (PFS) $(\mathrm{HR}=0.68,95 \% \mathrm{CI}=0.49$ $0.95)$ and a significantly better $\mathrm{OS}(\mathrm{HR}=0.68$, 95\% CI $=0.49$ 0.95 ), associated with increased, but manageable toxicity. Further investigations are needed to clarify the role of adjuvant chemotherapy after CCRT, especially in patients with positive lymph nodes, large tumor size or stage III-IVa disease (10).

Heterogeneity of cancer cells and their microenvironment influences patient response to radiotherapy, and therefore a non-invasive tool able to assess such heterogeneity, prior to or early during treatment, might deeply impact the management of individual patients, thus allowing to tailor therapy within a precision medicine paradigm (11). Radiomics is the high-throughput extraction of large amounts 
of features from radiographic images, and the detection of radiomics features of tumor heterogeneity could offer very promising predictive and prognostic markers in several tumors, including cervical cancer (12-16).

\section{Neoadjuvant Chemotherapy Followed by Radiotherapy}

The use of neoadjuvant chemotherapy (NACT) before radiotherapy has since long been debated. The meta-analysis of 18 randomized trials comparing NACT followed by radical radiotherapy versus radical radiotherapy in patients with locally advanced cervical cancer showed an OS advantage for NACT arm in trials with chemotherapy cycle lengths $\leq 14$ days $(\mathrm{HR}=0.83,95 \% \mathrm{CI}=0.69-1.00, p=0.046)$ or CDDP dose intensities $\geq 25 \mathrm{mg} / \mathrm{m}^{2} /$ week $(\mathrm{HR}=0.91,95 \% \mathrm{CI}=0.78-1.05$, $p=0.20)$ (17). Conversely, NACT was detrimental in trials with chemotherapy cycle lengths $>14$ days $(\mathrm{HR}=1.25,95 \% \mathrm{CI}=1.07$ $1.46, p=0.005)$ or CDDP dose intensities $<25 \mathrm{mg} / \mathrm{m}^{2} /$ week $(\mathrm{HR}=1.35,95 \% \mathrm{CI}=1.11-1.14, p=0.002)$. Although no study has compared CDDP- based versus carboplatin (CBDCA)-based chemotherapy in the neoadjuvant setting, a Japanese randomized phase III trial including 253 patients with recurrent or metastatic cervical cancer failed to evidence a difference in OS between the patients treated with paclitaxel (PTX) (135 $\mathrm{mg} / \mathrm{m}^{2} 24-\mathrm{h}$ infusion day 1$)$ plus CDDP $\left(50 \mathrm{mg} / \mathrm{m}^{2}\right.$ day 2$)$ and those treated with PTX $\left(175 \mathrm{mg} / \mathrm{m}^{2} 3-\mathrm{h}\right.$ infusion day 1) plus CBDCA area under curve (AUC) $5 \mathrm{mg} / \mathrm{ml} / \mathrm{min}$ day 1 ) every 3 weeks (18). However, among the patients who had not received prior CDDP, OS was worse for PTX plus CBDCA arm (13.0 versus 23.2 months; $\mathrm{HR}=1.571$; 95\% $\mathrm{CI}=1.062-2.324$ ).

In a pilot study NACT with dose-dense weekly PTX (60 $\mathrm{mg} / \mathrm{m}^{2}$ ) plus CBDCA (AUC2) for 6 cycles obtained a complete response in 2 and a partial response in 17 out of 28 patients with locally advanced cervical cancer, with an overall response rate of $67.8 \%$ (19). After a mean interval of 15 days (range $=7$ 23 days), 24 patients received standard CDDP-based CCRT, 23 of these $(95.8 \%)$ achieved a complete response, and 22 were still in complete response after a median follow-up of 12 months. Grade 3-4 neutropenia was the main hematological toxicity seen in $32.1 \%$ and $29.2 \%$ of patients, respectively, during NACT and CCRT.

A British single-arm phase II trial included 46 patients with FIGO stage Ib2-IVa cervical cancer scheduled to receive dosedense weekly PTX $\left(80 \mathrm{mg} / \mathrm{m}^{2}\right.$ ) plus CBDCA (AUC2) for six cycles followed by standard CDDP-based CCRT (20). Thirtyseven patients $(80.4 \%)$ completed all six cycles of NACT, 45 $(97.8 \%)$ had radiotherapy, and $36(78.2 \%)$ received four to six cycles of CDDP during radiotherapy. A complete and a partial response were achieved in $2(4.3 \%)$ and $30(65.2 \%)$ patients after NACT, and, respectively, in 29 (63.0\%) and $10(21.7 \%)$ patients twelve weeks after CCRT completion. Grade 3-4 hematological and non-hematological adverse events occurred in $5(10.9 \%)$ and $4(8.7 \%)$ patients during NACT and, respectively, in $19(41.3 \%)$ and $10(21.7 \%)$ patients during CCRT. In the entire cohort, 3- and 5-year PFS rates were $68 \%$ and the 3-year and 5-year OS rates were $67 \%$, respectively, with no deaths or progression between 3 and 5 years. These clinical outcomes were better than those of the 1243 patients treated with radiotherapy or CCRT in 42 UK centers (21). In fact, the 5-year OS of these historical controls assessed by a Royal College of Radiologists' audit was $56 \%$. The phase II multicenter randomized trial INTERLACE (Induction Chemotherapy Plus Chemoradiation as First Line Treatment for Locally Advanced Cervical Cancer, NCT01566240) is currently comparing the standard CCRT (external beam radiotherapy up to a dose of 40-50.4 Gy in 20-28 fractions concurrent with CDDP $40 \mathrm{mg} / \mathrm{m}^{2} /$ week for 5 cycles plus brachytherapy) versus induction chemotherapy consisting of weekly PTX $\left(80 \mathrm{mg} / \mathrm{m}^{2}\right.$ ) plus CBDCA (AUC2) for 6 cycles followed by the same CCRT.

\section{Neoadjuvant Chemotherapy Followed by Radical Surgery}

Standard chemotherapy regimens. Platinum-based NACT followed by radical hysterectomy has been proposed as an alternative approach to radiotherapy or CCRT in locally advanced cervical cancer, especially of squamous cell histology, with objective response rates ranging from $69.4 \%$ to $90.2 \%$, pathological optimal response rates ranging from $21.3 \%$ to $48.3 \%, 5$-year DFS rates ranging from $55.4 \%$ to $71 \%$ and 5-year OS rates ranging from $58.9 \%$ to $81 \%$, respectively (22-32) (Table I).

The meta-analysis of 6 randomized trials including patients with early or locally advanced cervical cancer found that patients who underwent NACT plus radical hysterectomy had better PFS $(\mathrm{HR}=0.75,95 \% \mathrm{CI}=0.61-0.93, p=0.008)$ and $\mathrm{OS}$ $(\mathrm{HR}=0.77,95 \% \mathrm{CI}=0.62-0.96, p=0.02)$ compared to those who underwent primary radical hysterectomy, regardless of total CDDP dose, chemotherapy cycle length or tumor stage (33). NACT significantly decreased tumor size, stromal invasion depth, parametrial infiltration, lymph-vascular space involvement and nodal metastases, thus reducing the need of adjuvant radiotherapy $(22,27,28,33,34)$.

Age $>35$ years $(25)$, smaller tumor size $(24,25,28)$, less advanced stage $(24,26,28,35)$, lack of nodal metastases $(24$, $28,30)$, squamous cell histology (28), objective clinical response $(28,30)$, and optimal pathological response $(26,35$, 36) represented favorable prognostic variables for OS of patients treated with this chemo-surgical approach. Colombo et al. (36) retrospectively assessed 100 advanced cervical cancer patients who received CDDP plus vincristine (VCR) plus bleomycin (BLEO) prior to radical hysterectomy. They found that the achievement of an optimal pathological response (i.e. a complete disappearance of tumor in the cervix 
Table I. Prognosis of patients with locally advanced cervical cancer treated with conventional neo-adjuvant chemotherapy followed by radical hysterectomy.

\begin{tabular}{|c|c|c|c|c|c|c|}
\hline Authors & Stage & Histology & $\mathrm{CT}$ regimen & pts & DFS & OS \\
\hline Sardi (22) & $\mathrm{Ib}>2 \mathrm{~cm}$ & SCC & $\mathrm{CDDP}+\mathrm{VCR}+\mathrm{BLEO}^{\mathrm{a}}$ & $\begin{array}{l}\mathrm{Ib}_{1} 41 \\
\mathrm{Ib}, 61\end{array}$ & $\begin{array}{l}\text { After } 8 \text { years of follow-up } \\
\text { After } 9 \text { years of follow-up }\end{array}$ & $\begin{array}{l}\text { OS: } 82 \% \\
\text { OS: } 80 \%\end{array}$ \\
\hline Chang (23) & Ib2-IIa2 & $\mathrm{SCC}, \mathrm{AD}-\mathrm{ADS}$ & $\mathrm{CDDP}+\mathrm{VCR}+\mathrm{BLEO}^{\mathrm{b}}$ & 68 & & $5-y: 70 \%$ \\
\hline Benedetti (24) & Ib-III & SCC & different platinum-based regimen ${ }^{\mathrm{c}}$ & 210 & $5-y: 55.4 \%$ & $5-y: 58.9 \%$ \\
\hline Huang (25) & Ib2-IIa2 & SCC, AD-ADS & $\mathrm{CDDP}+\mathrm{VCR}+\mathrm{BLEO}^{\mathrm{d}}$ & 162 & $5-\mathrm{y}: 65 \%$ & $5-y: 69 \%$ \\
\hline Buda (26) & Ib2-IV & SCC & $\begin{array}{c}\mathrm{CDDP}+\mathrm{PTX}+\mathrm{IFO}^{\mathrm{e}} \\
\mathrm{CDDP}^{\mathrm{IFFO}}{ }^{\mathrm{f}}\end{array}$ & $\begin{array}{c}96 \\
108\end{array}$ & $\begin{array}{l}4-y: 71 \% \\
4-y: 65 \%\end{array}$ & \\
\hline Katzumata (27) & Ib2-IIb & SCC & $\mathrm{BLEO}+\mathrm{VCR}+\mathrm{MIT}-\mathrm{C}+\mathrm{CDDPg}$ & 67 & $5-y: 59.9 \%$ & $5-y: 70 \%$ \\
\hline Chen (28) & Ib2-IIb & $\mathrm{SCC}, \mathrm{AD}, \mathrm{ADS}$ & $\mathrm{CDDP}+\mathrm{MIT}-\mathrm{C}+5-\mathrm{FU}^{\mathrm{h}}$ & 72 & & $4-y: 71 \%$ \\
\hline Lissoni (29) & Ib2-IVa & SCCA & $\begin{array}{c}\mathrm{CDDP}+\mathrm{PTX}+\mathrm{IFO}^{\mathrm{e}} \\
\mathrm{CDDP}+\mathrm{PTX}^{\mathrm{i}}\end{array}$ & $\begin{array}{l}74 \\
80\end{array}$ & $\begin{array}{l}5-y: 71 \% \\
5-y: 64 \%\end{array}$ & $\begin{array}{l}5-\mathrm{y}: 78 \% \\
5-\mathrm{y}: 72 \%\end{array}$ \\
\hline Angioli (30) & Ib2-IIb & SCC, AD-ADS & $\mathrm{CDDP}+\mathrm{PTX}^{1}$ & 115 & $5-y: 61 \%$ & $5-y: 77 \%$ \\
\hline Shoji (31) & Ib2-IIIb & SCC & $\mathrm{CDDP}+\mathrm{CPT}-11^{\mathrm{m}}$ & 42 & $5-y: 67.2 \%$ & $5-y: 68 \%$ \\
\hline Mori (32) & $\mathrm{Ib} 2-\mathrm{II} b>4 \mathrm{~cm}$ & SCC & Nedaplatin+CPT-11 ${ }^{\mathrm{n}}$ & 32 & 5-y: 78.8 & 5 -y: $89.7 \%$ \\
\hline
\end{tabular}

${ }^{\mathrm{a} C D D P} 50 \mathrm{mg} / \mathrm{m}^{2} \mathrm{~d} 1+\mathrm{VCR} 1 \mathrm{mg} / \mathrm{m}^{2} \mathrm{~d} 1+$ BLEO $25 \mathrm{mg} / \mathrm{m}^{2} \mathrm{~d} 1-3 \mathrm{q} 10$ for 3 cycles. ${ }^{\mathrm{b}} \mathrm{CDDP} 50 \mathrm{mg} / \mathrm{m}^{2} \mathrm{~d} 1+\mathrm{VCR} 1 \mathrm{mg} / \mathrm{m}^{2} \mathrm{~d} 1+\mathrm{BLEO} 25 \mathrm{mg} / \mathrm{m}^{2} \mathrm{~d} 2-$ $4 \mathrm{q}$ for 3 cycles. ${ }^{\mathrm{c} M i n i m a l}$ requirements were CDDP containing regimen with a $\geq 240 \mathrm{mg} / \mathrm{m}^{2}$ total CDDP dose with a maximum of two additional drugs, administered over a period of 6 to 8 weeks. ${ }^{\mathrm{d}}$ CDDP $50 \mathrm{mg} / \mathrm{m}^{2} \mathrm{~d} 1+\mathrm{VCR} 1 \mathrm{mg} / \mathrm{m}^{2} \mathrm{~d} 1+$ BLEO $25 \mathrm{mg} / \mathrm{m}^{2} \mathrm{~d} 1-3 \mathrm{q} 10$ for 3 cycles. ${ }^{\text {ePTX }} 175 \mathrm{mg} / \mathrm{m}^{2} \mathrm{~d} 1$ + IFO $5 \mathrm{~g} / \mathrm{m}^{2}$ (+ mesna $\left.5 \mathrm{~g} / \mathrm{m}^{2}\right) \mathrm{d} 1+$ CDDP $75 \mathrm{mg} / \mathrm{m}^{2} \mathrm{~d} 2 \mathrm{q} 21 \times 3$ cycles. fIFO $5 \mathrm{~g} / \mathrm{m}^{2}$ (+mesna $\left.5 \mathrm{~g} / \mathrm{m}^{2}\right) \mathrm{d} 1+$ CDDP $75 \mathrm{mg} / \mathrm{m}^{2} \mathrm{~d} 2 \mathrm{q} 21 \times 3 \mathrm{cycles}$. gBLEO $7 \mathrm{mg} \mathrm{d} 1-5+$ VCR $0.7 \mathrm{mg} / \mathrm{m}^{2} \mathrm{~d} 5+$ MIT-C $7 \mathrm{mg} / \mathrm{m}^{2} \mathrm{~d} 5+$ CDDP $14 \mathrm{mg} / \mathrm{m}^{2}$ d 1-5, q21 $\times 2-4$ cycles. hCDDP $100 \mathrm{mg} / \mathrm{m}^{2} \mathrm{~d} 1+\mathrm{MIT}-\mathrm{c} 4 \mathrm{mg} / \mathrm{m}^{2}$

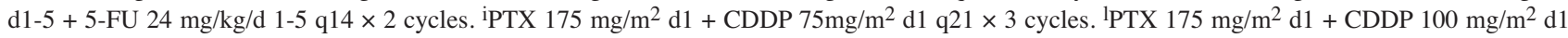
q $21 \times 3$ cycles. ${ }^{\mathrm{m}} \mathrm{CDDP} 70 \mathrm{mg} / \mathrm{m}^{2} \mathrm{~d} 1+$ CPT-11 $70 \mathrm{mg} / \mathrm{m}^{2} \mathrm{~d} 1$ and $8 \mathrm{q} 21 \times 2$ cycles. ${ }^{\mathrm{n}} \mathrm{CPT}-11$ Irinotecan $60 \mathrm{mg} / \mathrm{m}^{2} \mathrm{~d} 1 \mathrm{and} 8+$ nedaplatin $80 \mathrm{mg} / \mathrm{m}^{2}$ d1 q21 $\times 2$ cycles. pts, Patients; DFS, disease-free survival; OS, survival; SCC, squamous cell cervical carcinoma; CDDP, cisplatin; VCR, vincristine; Bleo, bleomicin; FU, follow-up; AD, adenocarcinoma, ADS, adenosquamous; PTX, paclitaxel, IFO, ifosfamide; MIT-C, mitomicine; CPT, irinotecan.

with negative nodes or residual disease with less than $3 \mathrm{~mm}$ stromal invasion) was an independent prognostic factor for OS. In the Studio Neo-Adjuvante Portio Italian Collaborative Study (SNAP01), which compared the combination of PTX plus ifosfamide (IFO) plus CDDP (TIP regimen) versus IFO plus CDDP (IP regimen) before radical surgery, an optimal pathological response was an independent predictor of OS with an HR of 5.88 (95\%CI=2.50-13.84) (26).

A subsequent Italian multicenter retrospective study, including 333 patients with FIGO stage Ib2-IIb cervical cancer treated with different platinum-based regimens followed by radical surgery, confirmed that the pathological response to NACT was an independent prognostic variable for both PFS and OS (35). Patients who did not obtain an optimal response had a 2.757 -fold higher risk of recurrence and a 5.413-fold higher risk of death than those who obtained an optimal response.

The optimal pathological response rate was $48.3 \%$ in the 89 patients of the TIP arm versus $23.0 \%$ in the 100 patients of the IP arm [odds ratio $(\mathrm{OR})=3.22 ; 95 \% \mathrm{CI}=1.69-5.88$ ] in the SNAP01 trial, and G3-4 neutropenia, thrombocytopenia and anemia were detected in $59.1 \%, 14.0 \%$ and $18.3 \%$ of the former, and, respectively, in $40.6 \%, 7.0 \%$ and $10.9 \%$ of the latter ( $p=0.02, p=0.02$, and $p=0.05$ ) (26). The optimal pathological response rate was $42.9 \%(95 \% \mathrm{CI}=31.1 \%-55.2 \%)$ in the 70 patients treated with TIP versus $25.3 \%(95 \% \mathrm{CI}=16.0 \%-36.7 \%)$ in the 75 patients treated with PTX+CDDP (TP regimen) in the SNPA02 trial (29). Therefore, TP activity was below expectation since the lower $95 \%$ confidence limit of the optimal response rate did not achieve the pre-specified minimum requirement of $22 \%$. TIP confirmed its activity but it was associated with a significant higher incidence of grade 3-4 leukopenia, neutropenia, thrombocytopenia, and anemia than TP $(53.4 \%$ versus $6.4 \%, p<0.0001 ; 76.4 \%$ versus $25.6 \%, p<0.0001 ; 23.3 \%$ versus $1.3 \%, p<0.0001$; and $32.8 \%$ versus $16.7 \%, p=0.02$, respectively).

The few available data about the activity of NACT followed by radical surgery in locally advanced cervical adenocarcinoma showed objective response rates ranging from $50.0 \%$ to $92.8 \%$ and optimal pathological response rates usually lower than $20 \%$ (37-45). Tabata et al. (41) reported a pathological optimal response in $57 \%$ of 14 patients, but the authors also included cases with microscopic residual disease $<5 \mathrm{~mm}$ among optimal responders.

He et al. (46), who analyzed 2 randomized trials and 9 observational studies including a total of 1,559 patients, failed to evidence any difference in terms of either overall response rate or complete response rate to NACT between squamous and non-squamous carcinomas. Conversely, PFS and OS were better for squamous cell carcinomas. On the other hand adenocarcinoma of the uterine cervix can be classified into seven subtypes, i.e. endocervical (usual type), mucinous 
(gastric, intestinal, signet-ring cell), villoglandular, endometrioid, clear cell, serous, and mesonephric (47), and no meaningful clinical data are available on the sensitivity of each single subtype to chemotherapy $(48,49)$. Kojima et al. (48) assessed 52 patients with FIGO stage Ib2-IIb non-squamous cervical cancer who underwent NACT with docetaxel plus CBDCA, and found that response rates $(85.0 \%$ versus $46.2 \%$, $p=0.04), 5$-year PFS $(75.0 \%$ versus $38.5 \%, p=0.01)$ and 5 -year OS $(90.0 \%$ versus $36.9 \%, p<0.001)$ were better in the 20 patients with usual-type endocervical adenocarcinoma than in 13 patients with gastric-type mucinous carcinoma.

Predictive biological variables. Very few information is available on the biological variables predictive of response to NACT in cervical cancer. Zhang et al. (50) assessed the immunohistochemical expression of survivin, vascular endothelial growth factor (VEGF) and Ki-67 in 117 patients with FIGO stage $\mathrm{Ib}_{2}-\mathrm{IIa}_{2}$ squamous cell cervical cancer who received PTX $\left(135-175 \mathrm{mg} / \mathrm{m}^{2}\right.$ ) plus CBDCA (AUC4-5) every 3 weeks for 3 cycles followed by radical hysterectomy. The efficacy of treatment, defined as complete response, partial response or stable disease, correlated negatively with Ki-67 $(p<0.001)$, VEGF $(p<0.001)$ and survivin expression $(p<0.001)$ at univariate analysis, whereas only Ki-67 $(p<0.001)$ and survivin expression $(p=0.015)$ retained statistical significance at multivariate analysis.

Cervical cancer cells commonly harbor a defective $G_{1} / S$ checkpoint owing to the interaction of high-risk human papilloma virus E6-E7 proteins with p53 and retinoblastoma protein, and therefore the activation of the $\mathrm{G}_{2} / \mathrm{M}$ checkpoint could be critical for protecting neoplastic cells from chemotherapy (51). In a retrospective study, Vici et al. (52) assessed the levels of phosphorylated Wee1 (pWee1), a key $\mathrm{G}_{2} / \mathrm{M}$ checkpoint kinase, and $\gamma-\mathrm{H} 2 \mathrm{AX}$, a marker of DNA double-strand breaks, by immunohistochemistry in 52 patients with FIGO stage Ib-IIIa cervical cancer who underwent NACT with TIP regimen followed by radical hysterectomy. Elevated levels of pWee 1 and $\gamma-\mathrm{H} 2 \mathrm{AX}$ significantly correlated with a lower complete pathological response rate at multivariate analysis, thus suggesting that biomarkers of DNA damage and repair may represent predictive variables of chemoresistance in cervical cancer. This is the rational for a phase I trial with the Wee1 inhibitor Adavosertib in association with external beam irradiation and CDDP in cervical, vaginal, or uterine cancer (NCT03345784).

The Hippo pathway is an emerging growth control pathway involved in organ growth control, stem cell function, regeneration, and tumor suppression (53). This pathway negatively regulates the activity of YAP and TAZ, two homologous transcriptional co-activators, that when activated, promote cell proliferation, inhibit cell death, and are involved in the carcinogenesis of several malignancies (54-58). Immunohistochemical expression of TAZ and YAP was retrospectively performed in tissue samples from 50 patients with cervical cancer who underwent NACT with TIP regimen (n.41) or CDDP-based CCRT (n.9) followed by radical hysterectomy (59). TAZ expression in cancer cells correlated with a decreased complete pathological response rate $(p=0.041)$, whereas the expression of TAZ and YAP in tumor-infiltrating lymphocyte (TIL)s was associated with an increased complete pathological response rate $(p=0.083$ and $p=0.018$, respectively). Therefore, the concomitant evaluation of TAZ in tumor cells and in TILs might be a predictive factor of response to chemotherapy.

NACT in cervical cancer can induce anti-cancer immunity by altering TIL subsets $(60,61)$. CD8+ T cells are believed to be the front fighter against tumor, while Foxp3+ T cells can suppress the proliferation and activation of CD8+ T cells (62). Liang et al. (60) assessed pretreatment biopsies and radical hysterectomy specimens after two cycles of PTX $\left(175 \mathrm{mg} / \mathrm{m}^{2}\right)$ plus CDDP $\left(75 \mathrm{mg} / \mathrm{m}^{2}\right)$ in 137 patients with FIGO Ib2-IIa2 squamous cell cervical cancer. After NACT, Foxp3+ T cells reduced in both intratumoral $(p<0.001)$ and peritumoral areas $(p<0.001)$, whereas CD8+ $\mathrm{T}$ cell infiltration did not significantly change in both compartments. Patients who obtained a complete pathological response had post-NACT lower Foxp3 $+\mathrm{T}$ cells in both intratumoral $(p=0.045)$ and peritumoral areas $(p=0.014)$ when compared to those who did not, whereas there were no significant differences of intratumoral and peritumoral CD8+T cells between these two groups of patients. A high ratio of intratumoral CD8/peritumoral Foxp3 in residual tumors was an independent favorable prognostic variable for both PFS $(\mathrm{HR}=0.297 ; 95 \% \mathrm{CI}=0.109-0.810)$ and $\mathrm{OS} \quad(\mathrm{HR}=0.078$; $95 \% \mathrm{CI}=0.010-0.598)$. A pilot study on 13 primary cervical tumor samples, analyzed before and after NACT, noted that the combination of PTX plus CDDP caused a significant decrease in FoxP3+ T cells with increased CD8+ T cells (61). Conversely no effect on TILs was observed after CDDP alone.

Dose-dense chemotherapy regimens. The search for active and well tolerated drug combinations has stimulated the assessment of dose-dense or weekly regimens, such as weekly PTX plus CBDCA, that have shown promising results with favorable toxicity profile compared with standard CDDP-based combinations in patients with recurrent or metastatic cervical cancer (63). Dose-dense weekly PTX can allow a larger percentage of cancer cells to enter the vulnerable phase of their cell cycle when cytotoxic PTX concentrations are still present, and moreover the lower PTX doses and shorter infusion times can reduce myelosuppression and other toxicities associated with standard 3-weekly schedule (64). Persistent PTX and apoptotic cells have been detected in cervical cancer tissues of patients treated with weekly schedule up to 6-7 days after the last administration (65). 
Table II. Prognosis of patients with locally advanced cervical cancer treated with dose-dense neoadjuvant chemotherapy followed by radical hysterectomy.

\begin{tabular}{|c|c|c|c|c|c|c|}
\hline Authors & Stage & Histology & $\mathrm{CT}$ regimen & pts & DFS & OS \\
\hline Mori (66) & $\mathrm{Ib} 2-\mathrm{IIIb}$ & SCC, AD-ADS & CBDCA + PTX ${ }^{\mathrm{a}}$ & 30 & 5-y: 78.6 follow-up of & $5-\mathrm{y}: 81.8 \%$ \\
\hline Benedetti (67) & IIa- IIIb & SCC & $\mathrm{PTX}+\mathrm{CDDP} b$ & 22 & $\begin{array}{l}17 \text { months }(\text { range }=11-30), \\
16 / 19(84.2 \%) \text { NED }, 3 / 19 \\
(15.8 \%) \text { had recurrence and } \\
\text { one of these }(5.3 \%) \text { died }\end{array}$ & \\
\hline Tanioka (68) & Ib2-IIB & $\mathrm{SCC}, \mathrm{AD}, \mathrm{ADS}$ & $\mathrm{PTX}+\mathrm{CDDP}^{\mathrm{c}}$ & 50 & 5-y PFS: $88.2 \%$ & $5-\mathrm{y}: 88.2 \%$ \\
\hline Gadducci (69) & Ib1-IIb & $\mathrm{SCC}, \mathrm{AD}$ & $\mathrm{CBDCA}+\mathrm{PTX}^{\mathrm{d}}$ & 17 & $\begin{array}{c}\text { After a median interval of } \\
12 \text { months (3-22) from the } 1^{\text {st }} \\
\text { cycle of NACT, } 16(94.1 \%) \\
\text { pts: NED, } 1(5.9 \%) \text { developed } \\
\text { recurrent disease }\end{array}$ & \\
\hline Salihi (70) & Ib1-IIb & $\mathrm{SCC}, \mathrm{AD}-\mathrm{ADS}$ & $\mathrm{CBDCA}+\mathrm{PTX}^{\mathrm{e}}$ & 36 & $5-\mathrm{y}: 61.8 \%$ & $5 y: 70.8 \%$ \\
\hline
\end{tabular}

aPTX $60 \mathrm{mg} / \mathrm{m}^{2}+$ CBDCA AUC2 q7 for 6 cycles. bPTX $60 \mathrm{mg} / \mathrm{m}^{2}+$ CDDP50 mg/m $/ \mathrm{m}^{2}$ q 10 for 5 cycles. ${ }^{\mathrm{c}} \mathrm{CDDP} 75 \mathrm{mg} / \mathrm{m}^{2} \mathrm{~d} 1+\mathrm{PTX} 80 \mathrm{mg} / \mathrm{m}^{2} \mathrm{~d}$ $1,8,15$ q 21 for 3 cycles ( 2 more cycles after surgery).v dPTX $80 \mathrm{mg} / \mathrm{m}^{2}+$ CBDCA AUC2 q7 for 6 cycles. ${ }^{\text {ePTX }} 60 \mathrm{mg} / \mathrm{m}^{2}+$ CBDCA AUC2.7 q7 for 6 cycles for 9 cycles. pts, Patients; DFS, disease-free survival; OS, survival; SCC, squamous cell cervical carcinoma; AD, adenocarcinoma; ADS, adenosquamous; CBDCA, carboplatin; PTX, paclitaxel; CDDP, cisplatin; FU, follow-up; PFS, progression-free survival; NACT, neoadjuvant chemotherapy; NED, no evidence of disease, AUC, area under curve.

In the last years some phase II trials have investigated the activity of dose-dense regimens before radical surgery in patients with locally advanced cervical cancer, with overall response rates ranging from $52.6 \%$ to $94 \%$, optimal pathological response rates ranging from $17.6 \%$ to $50.0 \%, 5$ year DFS rates ranging from $61.8 \%$ to $88.2 \%$ and 5 -year OS rates ranging from $70.8 \% \%$ to $88.2 \%$, respectively (66-70) (Table II).

Mori et al. (66) obtained a clinical overall response in 26 of 30 patients $(86.7 \%)$. A complete response was seen in 2 patients (7\%), 1 of whom had a complete pathological response. A down-staging response was detected in 4 cases: 1 from IIIb to IIb, 1 from IIIa to IIb, 1 from IIb to complete clinical response and 1 from IIb to complete pathological response. The most common adverse events were hematological, and their levels were mostly acceptable. Twenty-eight patients underwent radical hysterectomy followed by adjuvant radiotherapy in 13 cases with high-risk factors. Five-year PFS and OS were $78.6 \%$ and $81.8 \%$, respectively, in the whole series, and $79.2 \%$ and $83.1 \%$ in the patients with stage Ib2-IIb disease. These results were similar to those obtained with definitive CCRT in a series of 49 patients with stage Ib2 cervical cancer, who had a 3-year PFS of $79 \%$ and a 3 -year OS of $86 \%$ (71).

In the study of Benedetti Panici et al. (67), 20 of 22 the patients $(91.9 \%)$ completed all five planned cycles of NACT, $19(86.4 \%)$ underwent radical surgery, and 6 of them $(31.6 \%)$ received adjuvant radiotherapy or CCRT. The overall response rate was $52.6 \%$ and the optimal pathological response rate was 31.6\%. Grade 3-4 leukopenia, neutropenia, thrombocytopenia and anemia developed in $4 \%, 14 \%, 0 \%$, and $4 \%$ of cases, respectively. No treatment-related death occurred, but one $(4.5 \%)$ patient had a transient ischemic attack and another one $(4.5 \%)$ had a myocardial infarction. Sixteen of the $19(84.2 \%)$ operated patients were alive with no evidence of disease after a median follow-up of 17 months.

In the study of Tomioka et al. (68) the overall response rates and complete pathological response rates were $94 \%$ and $28 \%$, respectively, and grade 3-4 neutropenia and febrile neutropenia occurred in $34 \%$ and $2 \%$ of cases, respectively. Adjuvant CCRT was administered to 2 patients. It is noteworthy that a complete pathological response was found in $32.5 \%$ of 40 patients with squamous cell carcinoma versus $10.0 \%$ of 10 patients with non-squamous cell carcinoma, and the corresponding 5-year OS rates were $97.5 \%$ and $50 \%$, respectively.

In our early experience, dose-dense chemotherapy obtained an overall response and optimal pathological response in $14(82.3 \%)$ and in $3(17.6 \%)$ of 17 patients, respectively (69). Histologically positive nodes, positive parametria and positive surgical margins were found in $12.5 \%, 18.7 \%$ and $6.2 \%$, respectively, of the 16 patients who underwent radical hysterectomy. Adjuvant CCRT or radiotherapy was given to 12 patients.

Sahili et al. (70) administered a modified dose-dense weekly PTX/CBDCA-based chemotherapy for 9 cycles to 36 patients, of which 9 had FIGO stage Ib1 (25.0\%), 7 had stage Ib2 (19.4\%), 3 had stage IIa (8.3\%), and 17 had stage IIb disease $(47.2 \%)$. RECIST responses were observed in 32 cases $(88.9 \%)$. Twenty-one patients underwent radical hysterectomy and 9 underwent conization, and histological 
examination revealed an optimal pathological response in 15 $(50.0 \%)$. Positive nodes, positive resection margins, and both positive nodes and resection margins were found in $16.7 \%$, $6.7 \%$, and $6.7 \%$, respectively, of the cases. Grade 3-4 neutropenia, grade 3 thrombocytopenia and grade 3 anemia were detected in $56 \%, 3 \%$ and $11 \%$, respectively, of patients, but there were no cases of neutropenic fever and chemotherapy-related death. Postoperative CCRT was administered to 11 patients.

\section{Neoadjuvant Chemotherapy Followed by Radical Surgery Versus Definitive Radiotherapy or Concurrent Chemoradiation}

The meta-analysis of 5 randomized trials including patients with locally advanced cervical cancer showed that NACT plus radical hysterectomy achieved better overall DFS $(\mathrm{HR}=0.68,95 \% \mathrm{CI}=0.56-0.82)$, loco-regional disease-free survival $(\mathrm{HR}=0.68,95 \% \mathrm{CI}=0.56-0.82)$, metastases-free survival $(\mathrm{HR}=0.63 ; 95 \% \mathrm{CI}=0.52-0.78)$ and $\mathrm{OS}(\mathrm{HR}=0.65$, $95 \% \mathrm{CI}=0.53-0.80)$ compared to definitive radiotherapy, although with heterogeneity in both the design and results (72). In the study of Benedetti Panici et al. (24), NACT arm experienced a significant better 5-year PFS (59.7\% versus $46.7 \%, p=0.02)$ and 5-year OS (64.7\% versus $46.4 \%$, $p=0.005$ ) compared to radiotherapy in patients with stage Ib2-IIb disease, but not in those with stage III disease (5-year $\mathrm{PFS}=41.9 \%$ versus $36.4 \%, p=0.29 ; 5$-year $\mathrm{OS}=41.6 \%$ versus $36.7 \%, p=0.36)$.

Gupta et al. (73) randomly allocated 635 patients with FIGO stage Ib2-II squamous cell cervical cancer to receive either 3 cycles of PTX $\left(175 \mathrm{mg} / \mathrm{m}^{2}\right.$ ) plus CBDCA (AUC5$6)$ every 3 weeks followed by radical surgery or standard CDDP-based CCRT. The 5-year DFS was significantly lower in the NACT arm than in CCRT arm (69.3\% versus $76.7 \%$; $\mathrm{HR}=1.38 ; 95 \% \mathrm{CI}=1.02-1.87 ; \quad p=0.038)$, whereas the corresponding 5-year OS rates were similar (75.4\% versus $74.7 \%, \quad \mathrm{HR}=1.025 ; 95 \% \mathrm{CI}=0.752-1.398 ; \quad p=0.87) . \quad$ In subgroup analyses, the detrimental effect of NACT plus surgery on DFS was even greater in patients with stage IIb disease $(67.2 \%$ versus $79.3 \%, \mathrm{HR}=1.90 ; 95 \% \mathrm{CI}=1.25-2.89$; $p=0.003$ ), whereas no significant DFS difference was observed between the two arms in patients with stage Ib2 or IIa disease. The rates of rectal toxicity (5.7\% versus $13.3 \%$, $p=0.002)$, bladder toxicity $(2.8 \%$ versus $7.3 \%, p=0.017)$ and vaginal toxicity $(19.9 \%$ versus $36.9 \%, p<0.001)$ at 90 days after treatment were significantly lower in the NACT arm, whereas 24 months after treatment there was no difference in rectal and bladder toxicities between the two groups and vaginal toxicity continued to be lower in the chemo-surgical arm $(12.0 \%$ versus $25.6 \%, p<0.001)$.

A European Organization for Research and Treatment of Cancer (EORTC) trial randomized 626 patients with FIGO stage $\mathrm{Ib}_{2}$-IIb cervical squamous cell carcinoma, adenocarcinoma or adenosquamous carcinoma to undergo either CDDP-based chemotherapy (with a cumulative minimum of $225 \mathrm{mg} / \mathrm{m}^{2}$ ) followed by radical hysterectomy or standard CDDP-based CCRT (74). Five-year PFS was $56.9 \%$ in NACT arm and $65.6 \%$ in CCRT arm ( $p=0.021)$, and the corresponding 5-year OS rates were $61.8 \%$ versus $67.7 \% \quad(p=0.154)(72)$. In subgroup analyses, the NACT arm showed a trend to better 5-year OS in patients with stage $\mathrm{Ib} 2$ disease $(82 \%$ versus $76 \%, \mathrm{HR}=0.89$, $95 \% \mathrm{CI}=0.48-1.65)$ and a trend to a worse 5 -year OS in patients with stage IIa2 disease $(69 \%$ versus $75 \%, \mathrm{HR}=1.21$, $95 \% \mathrm{CI}=0.59-2.49)$ and those with stage IIb disease (68\% versus $76 \%, \mathrm{HR}=1.32,95 \% \mathrm{CI}=0.93-1.88)$. Short-term grade 3-4 adverse events occurred more frequently in NACT arm $(41 \%$ versus $22 \%$ ), whereas grade 3-4 chronic toxicities were more frequent in CCRT arm (21\% versus $15 \%)$.

\section{Conclusion}

According to the results of the two recent randomized clinical trials, CCRT is superior to NACT followed by radical surgery in terms of PFS in patients with stage $\mathrm{Ib}_{2}$-II cervical cancer, and should represent the standard of treatment in this clinical setting. The role of NACT before CCRT or adjuvant chemotherapy after CCRT is still investigational.

According to the new 2018 FIGO staging classification for cervical cancer, stage $\mathrm{Ib}$ disease has been subdivided in three substages: $\mathrm{Ib}_{1}$, corresponding to an invasive carcinoma $\geq 5 \mathrm{~mm}$ depth of stromal invasion and $<2 \mathrm{~cm}$ in greatest dimension; $\mathrm{Ib}_{2}$, corresponding to an invasive carcinoma $\geq 2 \mathrm{~cm}$ and $<4 \mathrm{~cm}$ in greatest dimension; and stage $\mathrm{Ib}_{3}$, corresponding to an invasive carcinoma $\geq 4 \mathrm{~cm}$ in greatest dimension). The involvement of regional nodes at either imaging or pathologic examination has been described as stage IIIc (stage III $_{\mathrm{c} 1}$, pelvic node metastasis only; stage $\mathrm{III}_{\mathrm{c} 2}$, para-aortic node metastasis with or without pelvic node involvement) (75).

Disruption of the cervical stromal ring on magnetic resonance imaging (MRI) is strongly predictive of microscopic parametrial infiltration in patients with early invasive cervical cancer $(76,77)$. The patients with this MRI finding, if submitted to primary surgery, usually receive adjuvant radiotherapy or CCRT. Based on the 2018 FIGO classification, patients with stage $\mathrm{Ib}_{1}$ disease or with stage $\mathrm{Ib}_{2}-\mathrm{IIa}_{1}$ disease with intact stromal ring should undergo primary radical surgery and those with $\mathrm{Ib}_{2}-\mathrm{IIa}_{1}$ disease with disrupted stromal ring or with $\mathrm{Ib}_{3}$ disease could undergo either definitive CCRT or NACT followed by radical surgery. These latter treatments should be indicated especially in relatively young women, also for the lower incidence of long-term vaginal toxicity and compromise of sexual life. Patients with stage $\geq \mathrm{II}_{2}$ disease should undergo definitive CCRT. 
Clinical trials assessing NACT followed by surgery in cervical cancer have shown that TIP regimen has obtained the highest rates of optimal pathological response, associated with an elevated incidence of grade 3-4 neutropenia, thrombocytopenia and anemia $(26,29)$. The dose-dense weekly PTX/CBCDAbased regimen proposed by Salihi et al. (70) appeared to achieve optimal pathological response rates similar to those of TIP regimen with a better hematological toxicity profile. These very promising results compared with those obtained with other dosedense or weekly regimens could be due to both the inclusion of a $25 \%$ of patients with old FIGO stage $1 \mathrm{~b} 1$ disease and the administration of a higher number of weekly chemotherapy cycles before surgery (nine versus six). Further studies on larger series of well characterized patients are strongly warranted to better define the optimal regimen for patients with 2018 FIGO stage $\mathrm{Ib}_{2}-\mathrm{II}_{1}$ cervical cancer with disrupted stromal ring or with stage $\mathrm{Ib}_{3}$ cervical cancer selected to receive NACT followed by radical surgery.

\section{Conflicts of Interest}

The Authors declare no conflicts of interest.

\section{Authors' Contributions}

Conceptualization, Writing - original draft: Angiolo Gadducci; Data curation, formal analysis, methodology, writing, review and editing: Angiolo Gadducci and Stefania Cosio.

\section{References}

1 Bray F, Ferlay J, Soerjomataram I, Siegel RL, Torre LA and Jemal A: Global cancer statistics 2018: GLOBOCAN estimates of incidence and mortality worldwide for 36 cancers in 185 countries. CA Cancer J Clin 68(6): 394-424, 2018. PMID: 30207593. DOI: $10.3322 /$ caac. 21492

2 Rose PG, Ali S, Watkins E, Thigpen JT, Deppe G, ClarkePearson DL, Insalaco S and Gynecologic Oncology Group: Long-term follow-up of a randomized trial comparing concurrent single agent cisplatin, cisplatin-based combination chemotherapy, or hydroxyurea during pelvic irradiation for locally advanced cervical cancer: a Gynecologic Oncology Group Study. J Clin Oncol 25(19): 2804-2810, 2007. PMID: 17502627. DOI: 10.1200/JCO.2006.09.4532

3 Rose PG, Java J, Whitney CW, Stehman FB, Lanciano R, Thomas GM and DiSilvestro PA: Nomograms predicting progression-free survival, overall survival, and pelvic recurrence in locally advanced cervical cancer developed from an analysis of identifiable prognostic factors in patients from NRG Oncology/Gynecologic Oncology Group randomized trials of chemoradiotherapy. J Clin Oncol 33(19): 2136-2142, 2015. PMID: 25732170. DOI: 10.1200/JCO.2014.57.7122

4 Marth C, Landoni F, Mahner S, McCormack M, GonzalezMartin A and Colombo N; ESMO Guidelines Committee Cervical cancer: ESMO Clinical Practice Guidelines for diagnosis, treatment and follow-up. Ann Oncol 29(Suppl 4): iv262, 2018. PMID: 29741577. DOI: 10.1093/annonc/mdy 160
5 Cibula D, Pötter R, Planchamp F, Avall-Lundqvist E, Fischerova D, Haie Meder C, Köhler C, Landoni F, Lax S, Lindegaard JC, Mahantshetty U, Mathevet P, McCluggage WG, McCormack M, Naik R, Nout R, Pignata S, Ponce J, Querleu D, Raspagliesi F, Rodolakis A, Tamussino K, Wimberger P and Raspollini MR: The European Society of Gynaecological Oncology/European Society for Radiotherapy and Oncology/European Society of Pathology guidelines for the management of patients with cervical cancer. Radiother Oncol 127(3): 404-416, 2018. PMID: 29728273. DOI: 10.1016/j.radonc.2018.03.003

6 Koh WJ, Abu-Rustum NR, Bean S, Bradley K, Campos SM, Cho KR, Chon HS, Chu C, Clark R, Cohn D, Crispens MA, Damast S, Dorigo O, Eifel PJ, Fisher CM, Frederick P, Gaffney DK, Han E, Huh WK, Lurain JR, Mariani A, Mutch D, Nagel C, Nekhlyudov L, Fader AN, Remmenga SW, Reynolds RK, Tillmanns T, Ueda S, Wyse E, Yashar CM, McMillian NR and Scavone JL: Cervical Cancer, Version 3.2019, NCCN Clinical Practice Guidelines in Oncology. J Natl Compr Canc Netw 17(1): 64-84, 2019. PMID: 30659131. DOI: 10.6004/jnccn.2019.0001

7 Chemoradiotherapy for Cervical Cancer Meta-analysis Collaboration (CCCMAC): Reducing uncertainties about the effects of chemoradiotherapy for cervical cancer: individual patient data meta-analysis. Cochrane Database Syst Rev 20(1): CD008285, 2010. PMID: 20091664. DOI: 10.1002/14651858.CD008285

8 Dueñas-González A, Zarbá JJ, Patel F, Alcedo JC, Beslija S, Casanova L, Pattaranutaporn P, Hameed S, Blair JM, Barraclough $\mathrm{H}$ and Orlando M: Phase III, open-label, randomized study comparing concurrent gemcitabine plus cisplatin and radiation followed by adjuvant gemcitabine and cisplatin versus concurrent cisplatin and radiation in patients with stage IIB to IVA carcinoma of the cervix. J Clin Oncol 29(13): 1678-1685, 2011. PMID: 21444871. DOI: 10.1200/JCO.2009.25.9663

9 Hernández P, Olivera P, Dueñas-Gonzalez A, Pérez-Pastenes MA, Zárate A, Maldonado V and Meléndez-Zajgla Jl: Gemcitabine activity in cervical cancer cell lines Cancer Chemother Pharmacol 48(6): 488492, 2001 PMID: 11800030. DOI: 10.1007/s002800100370

10 Kumar L and Gupta S: Integrating chemotherapy in the management of cervical cancer: A critical appraisal. Oncology 91(Suppl 1): 8-17, 2016. PMID: 27464068. DOI: 10.1159/000447576

11 Mirnezami R, Nicholson J and Darzi A: Preparing for precision medicine. N Engl J Med 366(6): 489-491, 2012. PMID: 22256780. DOI: 10.1056/NEJMp1114866

12 Lambin P, Rios-Velazquez E, Leijenaar R, Carvalho S, van Stiphout RG, Granton P, Zegers CM, Gillies R, Boellard R, Dekker A and Aerts HJ: Radiomics: extracting more information from medical images using advanced feature analysis. Eur J Cancer 48(4): 441-446, 2012. PMID: 22257792. DOI: 10.1016/j.ejca.2011.11.036

13 Scalco E and Rizzo G: Texture analysis of medical images for radiotherapy applications. Br J Radiol 90(1070): 20160642, 2017. PMID: 27885836. DOI: 10.1259/bjr.20160642

14 Avanzo M, Stancanello J and El Naqa I: Beyond imaging: the promise of radiomics. Phys Med 38: 122-139, 2017. PMID: 28595812. DOI: 10.1016/j.ejmp.2017.05.071

15 Lucia F, Visvikis D, Desseroit MC, Miranda O, Malhaire JP, Robin P, Pradier O, Hatt M and Schick U: Prediction of outcome using pretreatment ${ }^{18} \mathrm{~F}-\mathrm{FDG}$ PET/CT and MRI radiomics in locally advanced cervical cancer treated with chemoradiotherapy. Eur J Nucl Med Mol Imaging 45(5): 768-786, 2018. PMID: 29222685. DOI: $10.1007 /$ s00259-017-3898-7 
16 Bowen SR, Yuh WT, Hippe DS, Wu W, Partridge SC, Elias S, Jia G, Huang Z, Sandison GA, Nelson D, Knopp MV, Lo SS, Kinahan PE and Mayr NA: Tumor radiomic heterogeneity: Multiparametric functional imaging to characterize variability and predict response following cervical cancer radiation therapy. J Magn Reson Imaging 47(5): 1388-1396, 2018. PMID: 29044908. DOI: $10.1002 /$ jmri.25874

17 Neoadjuvant Chemotherapy for Locally Advanced Cervical Cancer Meta-analysis Collaboration: Neoadjuvant chemotherapy for locally advanced cervical cancer: a systematic review and meta-analysis of individual patient data from 21 randomised trials. Eur J Cancer 39(17): 2470-2486, 2003. PMID: 14602133. DOI: $10.1016 / \mathrm{s} 0959-8049(03) 00425-8$

18 Kitagawa, Katsumata N, Shibata T, Kamura T, Kasamatsu T, Nakanishi T, Nishimura Ushijima K, Takano M, Satoh T and Yoshikawa H: Paclitaxel plus carboplatin versus paclitaxel plus cisplatin in metastatic or recurrent cervical cancer: The open-label randomized phase III trial JCOG0505. J Clin Oncol 33(19): 21292135, 2015. PMID: 25732161. DOI: 10.1200/JCO.2014.58.4391

19 Singh RB, Chander S, Mohanti BK, Pathy S, Kumar S, Bhatla N, Thulkar S, Vishnubhatla S and Kumar L: Neoadjuvant chemotherapy with weekly paclitaxel and carboplatin followed by chemoradiation in locally advanced cervical carcinoma: a pilot study. Gynecol Oncol 129(1): 124-128, 2013. PMID: 23353129. DOI: 10.1016/j.ygyno.2013.01.011

20 McCormack M, Kadalayil L, Hackshaw A, Hall-Craggs MA, Symonds RP, Warwick V, Simonds H, Fernando I, Hammond M, James L, Feeney A and Ledermann JA: A phase II study of weekly neoadjuvant chemotherapy followed by radical chemoradiation for locally advanced cervical cancer. Br J Cancer 108(12): 2464-2469, 2013. PMID: 23695016. DOI: 10.1038/bjc.2013.230

21 Vale CL, Tierney JF, Davidson SE, Drinkwater KJ and Symonds P: Substantial improvement in UK cervical cancer survival with chemoradiotherapy: results of a Royal College of Radiologists' audit. Clin Oncol (R Coll Radiol) 22(7): 590-601, 2010. PMID: 20594810. DOI: 10.1016/j.clon.2010.06.002

22 Sardi JE,Giaroli A, Sananes C, Ferreira M, Soderini A, Bermudez A, Snaidas L, Vighi S, Gomez Rueda N and di Paola G: Long-term follow-up of the first randomized trial using neoadjuvant chemotherapy in stage Ib squamous carcinoma of the cervix: the final results. Gynecol Oncol 67(1): 61-69, 1997. PMID: 9345358. DOI: 10.1006/gyno.1997.4812

23 Chang TC, Lai CH, Hong JH, Hsueh S, Huang KG, Chou HH, Tseng CJ, Tsai CS, Chang JT, Lin CT, Chang HH, Chao PJ, Ng KK, Tang SG and Soong YK: Randomized trial of neoadjuvant cisplatin, vincristine, bleomycin, and radical hysterectomy versus radiation therapy for bulky stage IB and IIA cervical cancer. J Clin Oncol 18(8): 1740-1747, 2000. PMID: 10764435. DOI: $10.1200 / \mathrm{JCO} .2000 .18 .8 .1740$

24 Benedetti-Panici P, Greggi S, Colombo A, Amoroso M, Smaniotto D, Giannarelli D, Amunni G, Raspagliesi F, Zola P, Mangioni $\mathrm{C}$ and Landoni F: Neoadjuvant chemotherapy and radical surgery versus exclusive radiotherapy in locally advanced squamous cell cervical cancer: results from the Italian multicenter randomized study. J Clin Oncol 20(1): 179-188, 2002. PMID: 11773168. DOI: 10.1200/JCO.2002.20.1.179

25 Huang HJ, Chang TC, Hong JH, Tseng CJ, Chou HH, Huang $\mathrm{KG}$ and Lai $\mathrm{CH}$ : Prognostic value of age and histologic type in neoadjuvant chemotherapy plus radical surgery for bulky ( $>4$ $\mathrm{cm}$ ) stage IB and IIA cervical carcinoma. Int J Gynecol Cancer
13(2): 204-211, 2003. PMID: 12657125. DOI: $10.1046 /$ j.15251438.2003.13004.x

26 Buda A, Fossati R, Colombo N, Fei F, Floriani I,Gueli Alletti D, Katsaros D, Landoni F, Lissoni A, Malzoni C, Sartori E, Scollo $\mathrm{P}$, Torri V, Zola P and Mangioni C: Randomized trial of neoadjuvant chemotherapy comparing paclitaxel, ifosfamide, and cisplatin with ifosfamide and cisplatin followed by radical surgery in patients with locally advanced squamous cell cervical carcinoma: the SNAP01 (Studio Neo-Adjuvante Portio) Italian Collaborative Study. J Clin Oncol 23(18): 4137-4145, 2005. PMID: 15961761. DOI: 10.1200/JCO.2005.04.172

27 Katsumata N, Yoshikawa H, Kobayashi H, Saito T, Kuzuya K, Nakanishi T, Yasugi T, Yaegashi N, Yokota H, Kodama S, Mizunoe T, Hiura M, Kasamatsu T, Shibata T and Kamura T: Phase III randomised controlled trial of neoadjuvant chemotherapy plus radical surgery vs radical surgery alone for stages IB2, IIA2, and IIB cervical cancer: a Japan Clinical Oncology Group trial (JCOG0102). Br J Cancer 108(10): 19571963, 2013. PMID: 23640393. DOI: 10.1038/bjc.2013.179

28 Chen $\mathrm{H}$, Liang $\mathrm{C}$, Zhang $\mathrm{L}$ and Huang $\mathrm{S}$ and $\mathrm{Wu} \mathrm{X}$ : Clinical efficacy of modified preoperative neoadjuvant chemotherapy in the treatment of locally advanced (stage IB2 to IIB) cervical cancer: randomized study. Gynecol Oncol 110(3): 308-315, 2008. PMID: 18606439. DOI: 10.1016/j.ygyno.2008.05.026

29 Lissoni AA, Colombo N, Pellegrino A, Parma G, Zola P, Katsaros D, Chiari S, Buda A, Landoni F, Peiretti M, Dell'anna T, Fruscio R, Signorelli M, Grassi R, Floriani I, Fossati R, Torri V and Rulli E: A phase II, randomized trial of neo-adjuvant chemotherapy comparing a three-drug combination of paclitaxel, ifosfamide, and cisplatin (TIP) versus paclitaxel and cisplatin (TP) followed by radical surgery in patients with locally advanced squamous cell cervical carcinoma: the Snap-02 Italian Collaborative Study. Ann Oncol 20(4): 660-665, 2009. PMID: 19181826. DOI: 10.1093/annonc/mdn690

30 Angioli R, Plotti F, Montera R, Aloisi A, Luvero D, Capriglione S, Terranova C, De Cicco Nardone C, Muzii L and BenedettiPanici P: Neoadjuvant chemotherapy plus radical surgery followed by chemotherapy in locally advanced cervical cancer. Gynecol Oncol 127(2): 290-296, 2012. PMID: 22819938. DOI: 10.1016/j.ygyno.2012.07.104

31 Shoji T, Takatori E, Furutake Y, Takada A, Nagasawa T, Omi H, Kagabu M, Honda T, Miura F, Takeuchi S, Kumagai S, Yoshizaki A, Sato A and Sugiyama T: Phase II clinical study of neoadjuvant chemotherapy with CDDP/CPT-11 regimen in combination with radical hysterectomy for cervical cancer with a bulky mass. Int J Clin Oncol 21(6): 1120-1127, 2016. PMID: 27342833. DOI: 10.1007/s10147-016-1008-7

32 Mori T, Makino H, Okubo T, Fujiwara Y, Sawada M, Kuroboshi $\mathrm{H}$, Tsubamoto H, Murakoshi H, Motohashi T, Kitawaki J and Ito $\mathrm{K}$ : Multi-institutional phase II study of neoadjuvant irinotecan and nedaplatin followed by radical hysterectomy and the adjuvant chemotherapy for locally advanced, bulky uterine cervical cancer: A Kansai Clinical Oncology Group study (KCOG-G1201). J Obstet Gynaecol Res 45(3): 671-678, 2019. PMID: 30575239. DOI: $10.1111 /$ jog. 13885

33 Rydzewska L, Tierney J, Vale CL and Symonds PR. Neoadjuvant chemotherapy plus surgery versus surgery for cervical cancer. Cochrane Database Syst Rev 12: CD007406, 2012. PMID: 23235641. DOI: 10.1002/14651858.CD007406.pub3 
34 Kim HS, Sardi JE, Katsumata N, Ryu HS, Nam JH, Chung HH, Park NH, Song YS, Behtash N, Kamura T, Cai HB and Kim JW: Efficacy of neoadjuvant chemotherapy in patients with FIGO stage IB1 to IIA cervical cancer: an international collaborative meta-analysis. Eur J Surg Oncol 39(2): 115-124, 2013. PMID: 23084091. DOI: $10.1016 /$ j.ejso.2012.09.003

35 Gadducci A, Sartori E, Maggino T, Zola P, Cosio S, Zizioli V, Lapresa M, Piovano E and Landoni F: Pathological response on surgical samples is an independent prognostic variable for patients with Stage Ib2-IIb cervical cancer treated with neoadjuvant chemotherapy and radical hysterectomy: an Italian multicenter retrospective study (CTF Study). Gynecol Oncol 131(3): 640-644, 2013. PMID: 24096111. DOI: 10.1016/j.ygyno.2013.09.029

36 Colombo N, Gabriele A, Lissoni A, Vecchione F, Zanetta G and Pellegrino A: Neoadjuvant chemotherapy (NACT) in locally advanced uterine cervical cancer (LAUCC): Correlation between pathological response and survival. Proc Am Soc Clin Oncol 17: 352a, 1998 (abstr 1359).

37 Hu T , Li S, Chen Y, Shen J, Li X, Huang K, Yang R, Wu L, Chen Z, Jia Y, Wang S, Cheng X, Han X, Lin Z, Xing H, Qu P, Cai H, Song X, Tian X, Xu H, Xu J, Zhang Q, Xi L, Deng D, Wang H, Wang S, Lv W, Wang C, Xie X and Ma D: Matchedcase comparison of neoadjuvant chemotherapy in patients with FIGO stage IB1-IIBcervical cancer to establish selection criteria. Eur J Cancer 48(15): 2353-2360, 2012. PMID: 22503395. DOI: 10.1016/j.ejca.2012.03.015

38 Benedetti-Panici P, Greggi S, Scambia G, Salerno MG, Amoroso M, Maneschi F, Cutillo G, Caruso A, Capelli A and Mancuso S: Locally advanced cervical adenocarcinoma: is there a place for chemo-surgical treatment? Gynecol Oncol 61(1): 44-49, 1996. PMID: 8626116. DOI: 10.1006/gyno.1996.0094

39 Zanetta G, Lissoni A, Gabriele A, Landoni F, Colombo A, Perego P and Mangioni C: Intense neoadjuvant chemotherapy with cisplatin and epirubicin for advanced or bulky cervical and vaginal adenocarcinoma. Gynecol Oncol 64(3): 431-435, 1997.

40 Iwasaka T, Fukuda K, Hara K, Yokoyama M, Nakao Y, Uchiyama M and Sugimori H: Neoadjuvant chemotherapy with mitomycin C, etoposide, and cisplatin for adenocarcinoma of the cervix. Gynecol Oncol 70(2): 236-240, 1998. PMID: 9740697. DOI: $10.1006 /$ gyno.1998.5079

41 Tabata T, Nishiura K, Yanoh K, Okugawa T, Obata H, Tanaka K and Toyoda N: A pilot study of neoadjuvant chemotherapy with mitomycin $\mathrm{C}$, etoposide, cisplatin, and epirubicin for adenocarcinoma of the cervix. Int J Clin Oncol 9(1): 59-63, 2004. PMID: 15162828. DOI: 10.1007/s10147-003-0363-3

42 Nagai T, Okubo T, Sakaguchi R, Seki H and Takeda S: Glassy cell carcinoma of the uterine cervix responsive to neoadjuvant intraarterial chemotherapy. Int J Clin Oncol 13(6): 541-544, 2008. PMID: 19093183. DOI: 10.1007/s10147-008-0776-0

43 Shoji T, Takatori E, Saito T, Omi H, Kagabu M, Miura F, Takeuchi $\mathrm{S}$ and Sugiyama T: Neoadjuvant chemotherapy using platinum- and taxane-based regimens for bulky stage Ib2 to IIb non-squamous cell carcinoma of the uterine cervix. Cancer Chemother Pharmacol 71(3): 657-662, 2013. PMID: 23263187. DOI: $10.1007 / \mathrm{s} 00280-012-2052-2$

44 Shimada M, Nagao S, Fujiwara K, Takeshima N, Takizawa K, Shoji T, Sugiyama T, Yamaguchi S, Nishimura R and Kigawa J: Neoadjuvant chemotherapy with docetaxel and carboplatin followed by radical hysterectomy for stage IB2, IIA2, and IIB patients with non-squamous cell carcinoma of the uterine cervix. Int J Clin Oncol 21(6): 1128-1135, 2016. PMID: 27380169. DOI: $10.1007 / \mathrm{s} 10147-016-1010-0$

45 Gadducci A, Landoni F, Cosio S, Zizioli V, Zola P, Ferrero AM, Lapresa MT, Maggino T and Sartori E: Neoadjuvant platinumbased chemotherapy followed by radical hysterectomy for stage Ib2-IIb adenocarcinoma of the uterine cervix - An Italian multicenter retrospective study. Anticancer Res 38(6): $3627-$ 3634, 2018. PMID: 29848719. DOI: 10.21873/anticanres.12637

46 He L, Wu L, Su G, Wei W, Liang L, Han L, Kebria M, Liu P, Chen $\mathrm{C}$, Yu Y, Zhong $\mathrm{M}$ and Wang W: The efficacy of neoadjuvant chemotherapy in different histological types of cervical cancer. Gynecol Oncol 134(2): 419-425, 2014. PMID: 24918866. DOI: 10.1016/j.ygyno.2014.06.001

47 Wilbur DC, Mikami Y, Colgan TJ, Park KJ, Ferenczy AS, Ronnett BM, Hirschowitz L, Schneider A, Loening T, Soslow R, McCluggage WG, Wells $M$ and Wright T: Glandular tumors and precursors. In: WHO classification of tumours of female reproductive organs. (Kurman RJ, Carcangiu ML, Herrington CS and Young RH, editors), Lyon: IARC Press; pp. 183-189, 2014.

48 Kojima A, Shimada M, Mikami Y, Nagao S, Takeshima N, Sugiyama T, Teramoto N, Kiyokawa T, Kigawa J and Nishimura R; Sankai Gynecology Study Group: Chemoresistance of gastric-type mucinous carcinoma of the uterine cervix: a study of the Sankai Gynecology Study Group. Int J Gynecol Cancer 28(1): 99-106, 2018. PMID: 29206664. DOI: 10.1097/IGC.0000000000001145

49 Gadducci A, Guerrieri ME and Cosio S: Adenocarcinoma of the uterine cervix: pathologic features, treatment options, clinical outcome and prognostic variables. Crit Rev Oncol Hematol 135: 103-114, 2019. PMID: 30819439. DOI: 10.1016/j.critrevonc. 2019.01.006

50 Zhang Y, Yan H, Li R, Guo Y and Zheng R: High expression of survivin predicts poor prognosis in cervical squamous cell carcinoma treated with paclitaxel and carboplatin. Medicine (Baltimore) 98(20): e15607, 2019. PMID: 31096466. DOI: 10.1097/MD.0000000000015607

51 Maugeri-Saccà $\mathrm{M}$, Bartucci $\mathrm{M}$ and De Maria R: Checkpoint kinase 1 inhibitors for potentiating systemic anticancer therapy. Cancer Treat Rev 39(5): 525-533, 2013. PMID: 23207059. DOI: 10.1016/j.ctrv.2012.10.007

52 Vici P, Buglioni S, Sergi D, Pizzuti L, Di Lauro L, Antoniani B, Sperati F, Terrenato I, Carosi M, Gamucci T, Dattilo R, Bartucci M, Vincenzoni C, Mariani L, Vizza E, Sanguineti G, Gadducci A, Vitale I, Barba M, De Maria R, Mottolese M and MaugeriSaccà M: DNA damage and repair biomarkers in cervical cancer patients treated with neoadjuvant chemotherapy: an exploratory analysis. PLoS One 11(3): e0149872, 2016. PMID: 26930412. DOI: $10.1371 /$ journal.pone. 0149872

53 Johnson R and Halder G: The two faces of Hippo: targeting the Hippo pathway for regenerative medicine and cancer treatment. Nat Rev Drug Discov 13(1): 63-79, 2014. PMID: 24336504. DOI: $10.1038 /$ nrd4161

54 Chan SW, Chan SW, Lim CJ, Guo K, Ng CP, Lee I, Hunziker W, Zeng Q and Hong W: A role for TAZ in migration, invasion, and tumorigenesis of breast cancer cells. Cancer Res 68(8): 2592-2598, 2008. PMID: 18413727. DOI: 10.1158/00085472.CAN-07-2696

55 Fernandez LA, Northcott PA, Dalton J, Fraga C, Ellison D, Angers S, Taylor MD and Kenney AM: YAP1 is amplified and up-regulated in hedgehog-associated medulloblastomas and mediates Sonic 
hedgehog-driven neural precursor proliferation. Genes Dev 23(23): 2729-2741, 2009. PMID: 19952108. DOI: 10.1101/gad.1824509

56 Zhou Z, Hao Y, Liu N, Raptis L, Tsao MS and Yang X: TAZ is a novel oncogene in non-small cell lung cancer. Oncogene 30(18): 2181-2186, 2011. PMID: 21258416. DOI: 10.1038/onc.2010.606

57 Hong W and Guan KL: The YAP and TAZ transcription coactivators: key downstream effectors of the mammalian Hippo pathway. Semin Cell Dev Biol 23(7): 785-793, 2012. PMID: 22659496. DOI: $10.1016 /$ j.semcdb.2012.05.004

58 Piccolo S, Dupont $\mathrm{S}$ and Cordenonsi M: The biology of YAP/TAZ: hippo signaling and beyond. Physiol Rev 94(4): 12871312, 2014. PMID: 25287865. DOI: 10.1152/physrev.00005.2014

59 Buglioni S, Vici P, Sergi D, Pizzuti L, Di Lauro L, Antoniani B, Sperati F, Terrenato I, Carosi M, Gamucci T, Vincenzoni C, Mariani L, Vizza E, Venuti A, Sanguineti G, Gadducci A, Barba M, Natoli C, Vitale I, Mottolese M, De Maria R and Maugeri-Saccà M: Analysis of the hippo transducers TAZ and YAP in cervical cancer and its microenvironment. Oncoimmunology 5(6): e1160187, 2016. PMID: 27471633. DOI: 10.1080/2162402X.2016.1160187

60 Liang Y, Lü W, Zhang X and Lü B: Tumor-infiltrating CD8+ and FOXP3+ lymphocytes before and after neoadjuvant chemotherapy in cervical cancer. Diagn Pathol 13(1): 93, 2018. PMID: 30474571. DOI: 10.1186/s13000-018-0770-4

61 Heeren AM, van Luijk IF, Lakeman J, Pocorni N, Kole J, de Menezes RX, Kenter GG, Bosse T, de Kroon CD and Jordanova ES: Neoadjuvant cisplatin and paclitaxel modulate tumorinfiltrating $\mathrm{T}$ cells in patients with cervical cancer. Cancer Immunol Immunother 68(11): 1759-1767, 2019. PMID: 31616965. DOI: 10.1007/s00262-019-02412-x

62 Gooden MJ, de Bock GH, Leffers N, Daemen T and Nijman HW: The prognostic influence of tumour-infiltrating lymphocytes in cancer: a systematic review with meta-analysis. Br J Cancer 105(1): 93-103, 2011. PMID: 21629244. DOI: 10.1038/bjc.2011.189

63 Torfs S, Cadron I, Amant F, Leunen K, Berteloot P and Vergote I: Evaluation of paclitaxel/carboplatin in a dose dense or weekly regimen in 66 patients with recurrent or primary metastatic cervical cancer. Eur J Cancer 48(9): 1332-1340, 2012. PMID: 22317951. DOI: 10.1016/j.ejca.2012.01.006

64 Thomas H and Rosenberg P: Role of weekly paclitaxel in the treatment of advanced ovarian cancer. Crit Rev Oncol Hematol 44(Suppl): S43-51, 2002. PMID: 12505598. DOI: 10.1016/s10408428(02)00103-8

65 Mori T, Kinoshita Y, Watanabe A, Yamaguchi T, Hosokawa K and Honjo $\mathrm{H}$ : Retention of paclitaxel in cancer cells for 1 week in vivo and in vitro. Cancer Chemother Pharmacol 58(5): 665672, 2006. PMID: 16534615. DOI: 10.1007/s00280-006-0209-6

66 Mori T, Hosokawa K, Sawada M, Kuroboshi H, Tatsumi H, Koshiba H, Okubo T and Kitawaki J: Neoadjuvant weekly carboplatin and paclitaxel followed by radical hysterectomy for locally advanced cervical cancer: long-term results. Int J Gynecol Cancer 20(4): 611-616, 2010. PMID: 20686381. DOI: 10.1111/IGC.0b013e3181d80aa9

67 Benedetti Panici P, Palaia I, Marchetti C, Ruscito I, Fischetti M, Musella A, Di Donato V, Perniola G, Vertechy L and Muzii L: Dose-dense neoadjuvant chemotherapy plus radical surgery in locally advanced cervical cancer: a phase II study. Oncology $89(2)$ : 103-110, 2015. PMID: 25924602. DOI: 10.1159/000381461

68 Tanioka M, Yamaguchi S, Shimada M, Nagao S, Takehara K, Nishimura M, Morita S, Negoro S, Fujiwara K and Kigawa J:
Cisplatin with dose-dense paclitaxel before and after radical hysterectomy for locally advanced cervical cancer: a prospective multicenter phase II trial with a dose-finding study. Med Oncol 34(8): 134, 2017. PMID: 28681218. DOI: 10.1007/s12032-0170992-4

69 Gadducci A, Barsotti C, Laliscia C, Cosio S, Fanucchi A, Tana $\mathrm{R}$ and Fabrini MG: Dose-dense paclitaxel- and carboplatin-based neoadjuvant chemotherapy followed by surgery or concurrent chemo-radiotherapy in cervical cancer: a preliminary Analysis. Anticancer Res 37(3): 1249-1255, 2017. PMID: 28314289. DOI: 10.21873/anticanres.11441

70 Salihi R, Leunen K, Moerman P, Amant F, Neven P and Vergote I: Neoadjuvant weekly paclitaxel-carboplatin is effective in stage I-II cervical cancer. Int J Gynecol Cancer 27(6): 1256-1260, 2017. PMID: 28574931. DOI: 10.1097/IGC.0000000000001021

71 Goksedef BP, Kunos C, Belinson JL and Rose PG: Concurrent cisplatin-based chemoradiation International Federation of Gynecology and Obstetrics stage IB2 cervical carcinoma. Am J Obstet Gynecol 200(2): 175.e1-5, 2009. PMID: 19091305. DOI: 10.1016/j.ajog.2008.08.055

72 Neoadjuvant Chemotherapy for Cervical Cancer Meta-Analysis Collaboration (NACCCMA) Collaboration: Neoadjuvant chemotherapy for locally advanced cervix cancer. Cochrane Database Syst Rev (2): CD001774, 2004. PMID: 15106161. DOI: $10.1002 / 14651858 . C D 001774 . p u b 2$

73 Gupta S, Maheshwari A, Parab P, Mahantshetty U, Hawaldar R, Sastri Chopra S, Kerkar R, Engineer R, Tongaonkar H, Ghosh J, Gulia S, Kumar N, Shylasree TS, Gawade R, Kembhavi Y, Gaikar M, Menon S, Thakur M, Shrivastava S and Badwe R: Neoadjuvant chemotherapy followed by radical surgery versus concomitant chemotherapy and radiotherapy in patients with stage Ib2, IIa, or IIb squamous cervical cancer: a randomized controlled trial. J Clin Oncol 36(16): 1548-1555, 2018. PMID: 29432076. DOI: $10.1200 / \mathrm{JCO} .2017 .75 .9985$

74 Kenter G, Greggi S, Vergote I, Katsaros D, Kobierski J, Massuger L, van Doorn HC, Landoni F, Van Der Velden J, Reed NS, Coens C, van Luijk I, Ottevanger PB and Casado A: Results from neoadjuvant chemotherapy followed by surgery compared to chemoradiation for stage Ib2-IIb cervical cancer, EORTC 55994. J Clin Oncol 37: abstr. 5503, 2019.

75 Bhatla N, Aoki D, Sharma DN and Sankaranarayanan R: Cancer of the cervix uteri. Int J Gynaecol Obstet 143(Suppl 2): 22-36, 2018. PMID: 30306584. DOI: 10.1002/ijgo.12611

76 Kong TW, Kim J, Son JH, Kang SW, Paek J, Chun M, Chang SJ and Ryu HS: Preoperative nomogram for prediction of microscopic parametrial infiltration in patients with FIGO stage IB cervical cancer treated with radical hysterectomy. Gynecol Oncol 142(1): 109-114, 2016. PMID: 27179979. DOI: 10.1016/j.ygyno.2016.05.010

77 Song J, Hu Q, Ma Z, Zhang J and Chen T: Value of diffusionweighted and dynamic contrast-enhanced MR in predicting parametrial invasion in cervical stromal ring focally disrupted stage IB-IIA cervical cancers. Abdom Radiol (NY) 44(9): 31663174, 2019. PMID: 31377834. DOI: 10.1007/s00261-01902107-y

Received March 2, 2020

Revised March 9, 2020

Accepted March 12, 2020 